\title{
Metodologia para obtenção de polígonos 3D a partir de nuvem de pontos LiDAR
}

\author{
Methodology for obtaining 3D polygons from LiDAR cloud points \\ Rafael Costa Cavalcanti \\ Ana Lúcia Bezerra Candeias \\ João Rodrigues Tavares Junior
}

\begin{abstract}
Pós-Graduação em Ciências Geodésicas e Tecnologias da Geoinformação
Departamento de Engenharia Cartográfica, Universidade Federal de Pernambuco - UFPE. Av. Prof. Moraes Rego, 1235 - Cidade Universitária, Recife - PE. CEP 50670-901. rafaelcc85@yahoo.com.br, analucia@ufpe.br, rodriguesjoao380@gmail.com
\end{abstract}

Recebido em 07/07/2015 - Aceito em 11/04/2016

Received on 07/07/2015 - Accepted on 04/11/2016

\begin{abstract}
RESUMO - Este artigo apresenta uma proposta metodológica de aquisição de polígonos 3D georreferenciados a partir da classificação e do tratamento de nuvens de pontos LiDAR de uma área da Universidade Federal de Pernambuco. O fatiamento do Modelo Digital de Elevação (MDE), a reclassificação, as ferramentas da Morfologia Matemática e a rotulação de componentes conexas foram utilizados na geração da máscara binária que representa a localização de edificação com ' 1 ' e onde não existe edificação com ' 0 '. A intersecção entre a máscara binária e a nuvem de pontos terá como resultado um arquivo vetorial de pontos com coordenadas $\mathrm{x}, \mathrm{y}$ e $\mathrm{z}$ referentes às edificações da área de estudo.
\end{abstract}

Palavras-chave: Extração de edificação, processamento de imagem, sensoriamento remoto

ABSTRACT - This paper presents a methodology for data acquiring 3D georeferenced polygons based on the classification and treatment of LiDAR cloud points of an area of Pernambuco's Federal University. Digital Elevation Model (DEM) slicing, reclassification, Mathematical Morphology tools and connected components are used to generate a binary mask that identifies building with ' 1 'o and not building with ' 0 '. The intersection between the binary mask with cloud of points will result in a vector file of points with coordinates $\mathrm{x}, \mathrm{y}$ and $\mathrm{z}$ of the buildings in the study area.

Keywords: Building extraction, image processing, remote sensing

\section{INTRODUÇÃO}

A partir da modelagem tridimensional é possível simular problemas relacionados ao meio ambiente. Essa modelagem pode ser obtida a partir de pontos LiDAR (Light Detection and Ranging).

Um exemplo da modelagem tridimensional usando dados LiDAR pode ser vista em Cavalcanti, Tavares Junior e Candeias (2013). Eles desenvolveram com esses dados LiDAR, uma simulação de mapeamento de risco de inundação para a bacia do Rio Una, Pernambuco.

Um outro exemplo é reconstrução de modelos tridimensionais de edificações, combinando dados de laser scanner aerotransportado com dados de imagens de alta resolução espacial desenvolvido em Botelho (2007) e que apresenta uma metodologia semi-automática de reconstrução de edificações.

Pacheco et al. (2011) apresentam uma classificação de pontos LiDAR para a geração do MDT (Modelo Digital de Terreno). Uma avaliação em função da precisão em altimetria e planimetria de dados LiDAR é apresentado em Becker e Centeno (2013). Eles mostram que, para o levantamento do relevo, mesmo de áreas relativamente planas, tem-se uma dependência das especificações do sensor utilizado no levantamento. $\mathrm{Ou}$ seja, a densidade de pontos pode não ser suficiente para se obter detalhamento das edificações, principalmente em áreas de grande densidade populacional.

A partir de um contrato com a Prefeitura da Cidade do Recife (PCR), o Instituto de Tecnologia de Pernambuco (ITEP) vem desenvolvendo a análise da qualidade do mapeamento de toda a área do município da Cidade do Recife. A partir dos testes desenvolvidos verificou-se discrepâncias com desvios padrão horizontais na ordem de $20 \mathrm{~cm}$ (ITEP, 2013), o que coloca estes dados dentro de uma precisão planimétrica suficiente para diversos estudos territoriais envolvendo áreas e volumes de construção.

Para que seja possível o estudo quantitativo das edificações presentes em uma área urbana, é necessária a extração destas edificações de toda a área de estudo, tendo em vista que, além das edificações, existem muitos outros elementos presentes na base planialtimétrica resultante de um levantamento LiDAR, a exemplo da vegetação.

O objetivo deste trabalho é definir um método para obtenção de polígonos referentes às edificações, a partir de uma malha de pontos obtidos por perfilamento a laser aerotransportado LiDAR.

Este artigo baseou-se em um trabalho prático desenvolvido na disciplina de Tópicos Especiais de Processamento de Dados na Pós-Graduação em Ciências 
Geodésicas e Tecnologias da Geoinformação para o $1^{\circ}$ semestre de 2014.

Na seção 2 desse texto tem-se as etapas do trabalho e tem-se que: com a intersecção entre o arquivo vetorial da nuvem de pontos LiDAR, a máscara binária adquirida pelo fatiamento do MDE, reclassificação, ferramentas da Morfologia Matemática, e a rotulação de componentes conexas, é possível separar os pontos referentes a edificações dos demais pontos presentes na nuvem de dados.

Em Haralick, Sternberg e Zhuang (1987), Candeias, (1997), Chen (2007), Candeias et al. (2013), tem-se um detalhamento sobre a Morfologia Matemática, e abordagem sobre o filtro de abertura e ínfimo que são utilizados neste trabalho.

\section{MÉTODO}

O método do trabalho foi dividido nas etapas mostradas a seguir e, que são detalhadas posteriormente, nessa seção.

a. Área de Estudo; b. Dados utilizados;

b.1 Nuvem de Pontos;

b. 2 Modelo Digital de Elevação;

c. Extração de informações do MDE por fatiamento;

d. Reclassificação do fatiamento;

e. Filtro de abertura (Morfologia Matemática);

f. Rotulação de componentes conexas;

g. Extração dos pontos utilizando a máscara;

\section{1 Área de estudo}

Para esta pesquisa foi selecionado um recorte da área da Universidade Federal de Pernambuco (Figura 1). Essa área foi escolhida por conter elementos comuns às diversas áreas do município do Recife. Isto permite uma simulação de um cenário padrão e, ao mesmo tempo, didático para a apresentação desta proposta metodológica.

Dentro do recorte encontram-se as edificações de Centro de Fisioterapia e Terapia Ocupacional da Universidade Federal de Pernambuco.

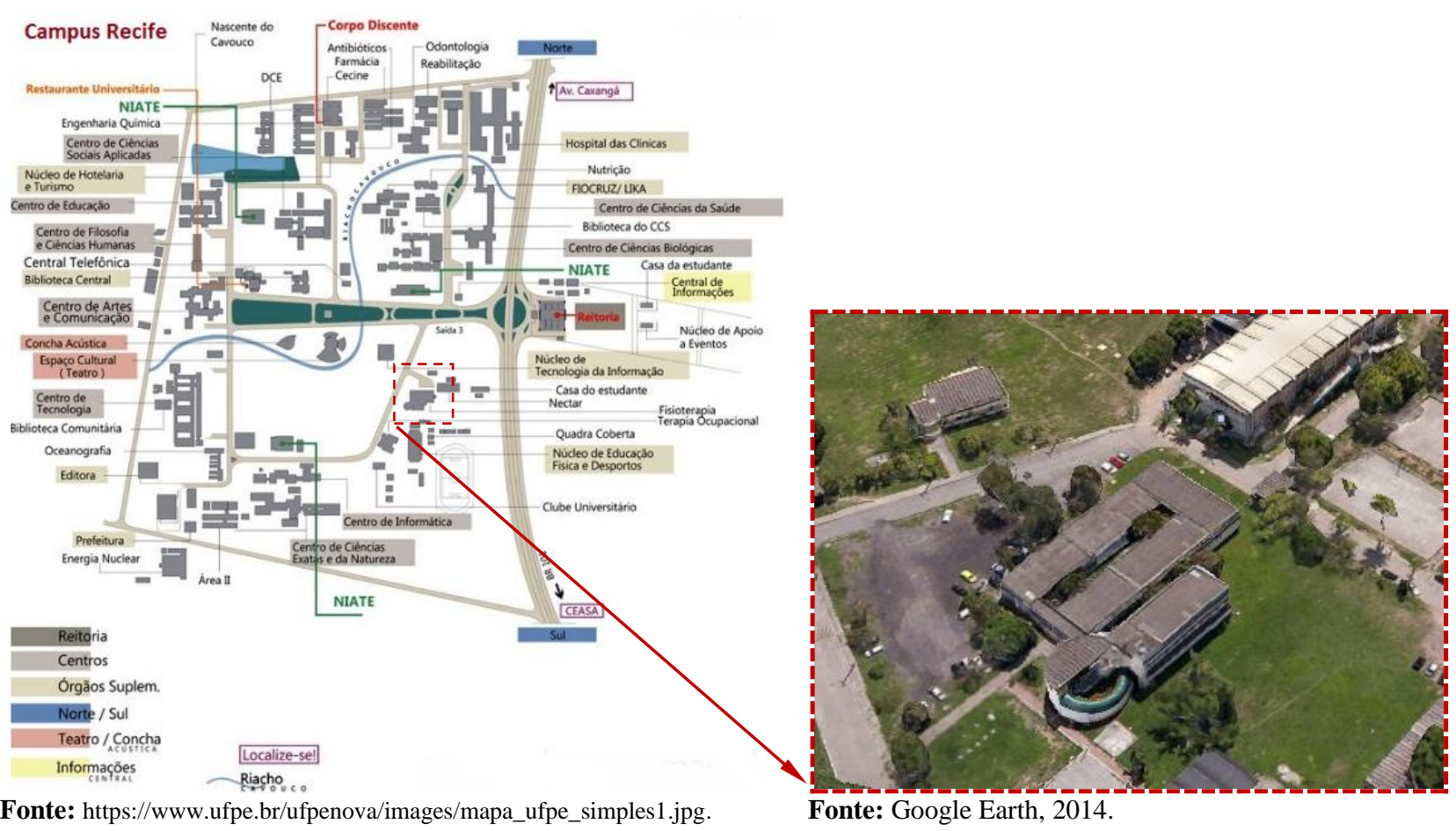

Fonte: Google Earth, 2014

Figura 1 - Visão panorâmica da área de estudo na UFPE das edificações de Centro de Fisioterapia e Terapia Ocupacional.

\subsection{Dados utilizados}

Como já foi mencionado anteriormente, os dados da base utilizados neste trabalho foram adquiridos a partir da contratação de levantamento aerofotogramétrico da cidade do Recife feito pela Prefeitura da Cidade do Recife no ano de 2013. A empresa contratada para o aerolevantamento entregou como resultado: as ortofotos, os modelos digitais de elevação, e modelo digital de terreno extraídos da nuvem de pontos. Estes produtos foram entregues a contratante PCR como produtos brutos e como resultados preliminares dos serviços contratados.

Tanto o MDE quanto a nuvem de pontos LiDAR, são utilizados nesta metodologia; o relacionamento entre estas duas informações permite a extração dos polígonos 3D georreferenciados das edificações. 


\subsubsection{Nuvem de Pontos}

Denota-se aqui o termo nuvem de pontos como a malha de pontos adquirida a partir da emissão e recepção do feixe de laser lançado pela aeronave no momento do vôo. Neste processo, feixes são enviados e retornam apenas os feixes refletidos na mesma direção de emissão.

Estes feixes de laser retornam com informações de coordenadas planialtimétricas do terreno em WGS-84, sendo isto possível por conta do sistema GNSS/IMU acoplado na aeronave. Além das coordenadas, cada ponto medido recebe informações de nível de intensidade do alvo refletido, o que permite a geração de imagens de composição entre estas camadas de informação, que facilitam a interpretação e visualização das feições do terreno. A Figura 2 mostra o resultado da representação hipsométrica de elevação $f_{1}$ das edificações de Centro de Fisioterapia e Terapia Ocupacional e seu entorno apresentados na Figura 1.

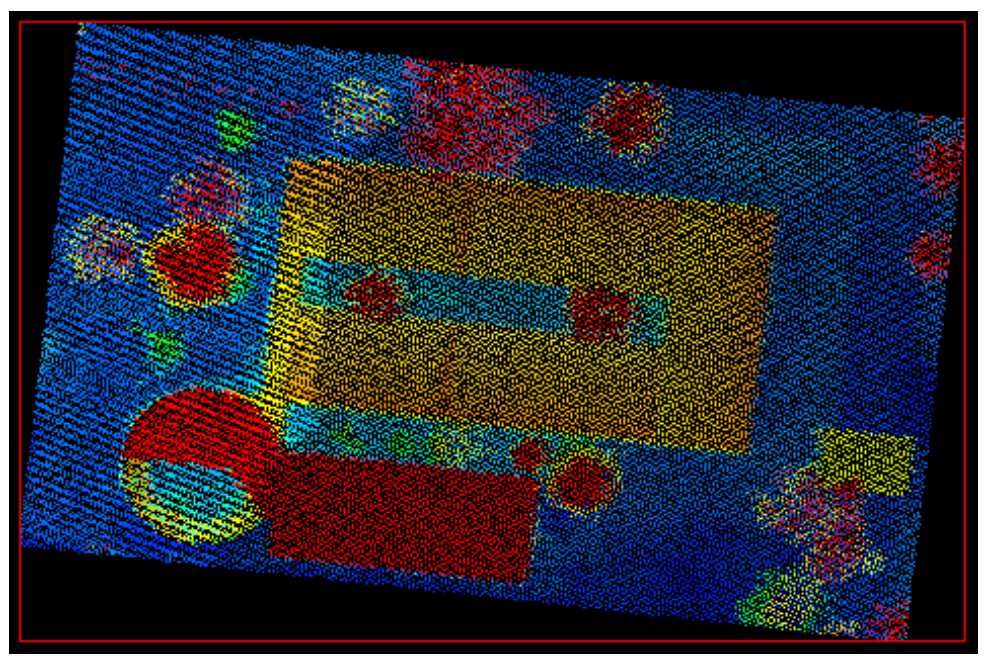

Figura 2 - Nuvem de pontos com representação hipsométrica de elevação $\left(f_{1}\right)$.

\subsubsection{Modelo Digital de Elevação.}

O Modelo Digital de Elevação é o modelo matricial gerado com base na nuvem de pontos LiDAR utilizando interpoladores. Este modelo normalmente é processado em formato GeoTIFF, e pode ser gerado pela maioria dos softwares de geoprocessamento.
A Figura 3 apresenta o Modelo Digital de Elevação com altimetria representada em escala de cinza e aqui denotado por $f_{2}$ e obtida pela Equação (1).

$$
f_{2}=\text { Interpolação }\left(f_{1}\right)
$$

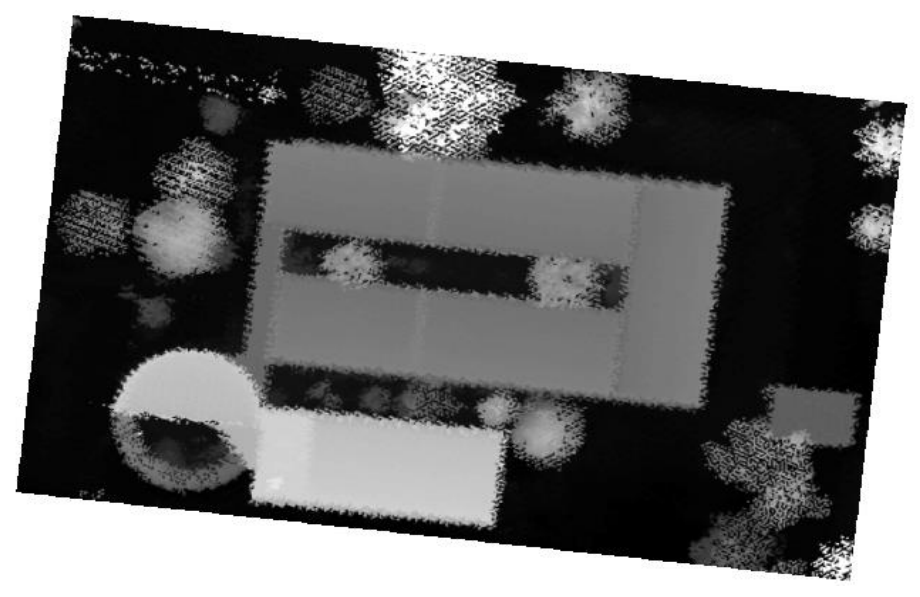

Figura 3 - Modelo Digital de Elevação (MDE) com altimetria representada em escala de cinza $\left(f_{2}\right)$. 


\subsection{Extração de informações do MDE por fatiamento}

A partir da técnica de fatiamento (slice), é possível dividir o MDE em diferentes classes com base na altura de cada ponto representado na nuvem de pontos. Esta divisão pode representar diferentes alvos da área de estudo. O processo de fatiamento permite que as classes sejam obtidas por intervalos. No caso aqui estudado utilizou-se o fatiamento por Natural Breaks, e foram utilizadas 8 classes.

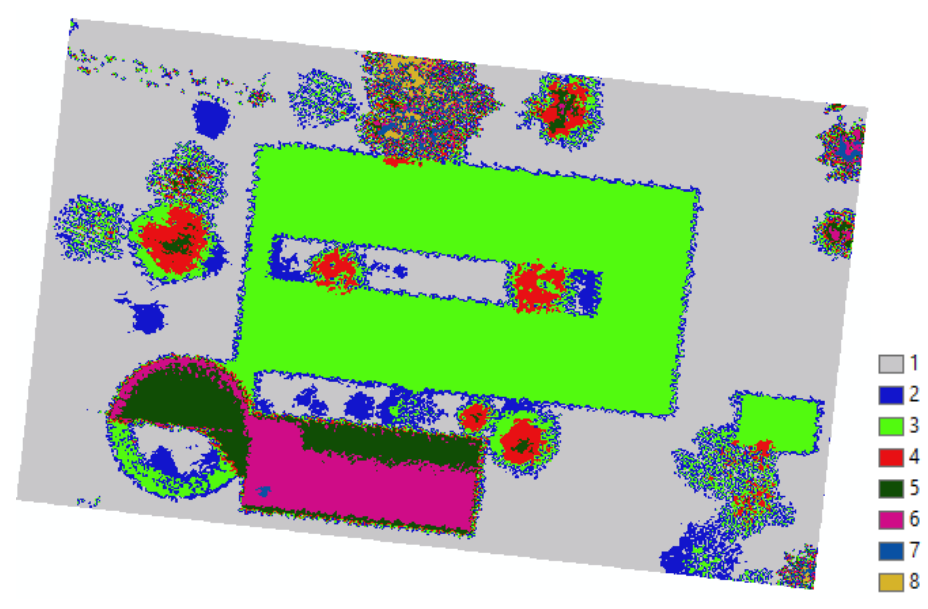

Figura 4 - Fatiamento do MDE utilizando oito classes com Natural Breaks $\left(f_{3}\right)$.

O método de classificação Natural Breaks cria intervalos de classificação (Slices) a partir de limiares naturais obtidas do histograma da imagem analisada (Equação 2). A Figura 4 mostra que apenas três das oito classes adquiridas representam telhados que são os alvos do estudo deste trabalho. Porém, as classes 3, 5 e 6 não representam apenas as edificações. Portanto, é necessário um processamento complementar para a extração dos telhados que será visto a seguir na seção 2.4 e denotado de reclassificação do fatiamento.

$$
f_{3}=\text { Slice }\left(" f_{2} ", 8,\right. \text {, NATURAL_BREAKS") }
$$

\subsection{Reclassificação do fatiamento}

A Figura 4 pode ser reclassificada para criação da máscara onde estão contidas as edificações. As classes de interesse recebem o valor 1 (Equação 3), e as de não interesse receberam o valor 0 (Equação 4). Como resultado tem-se a imagem mostrada na Figura 5. Observa-se pela Figura 5 que, parte da vegetação, também é classificada por ter altura equivalente a estes limiares selecionados.

$$
\begin{aligned}
& \text { classe de } f_{4}=1 \quad \text { se classe de } f_{3}=3,5 \text { ou } 6 \\
& \text { classe de } f_{4}=1 \quad \text { se classe de } f_{3} \neq 3,5 \text { ou } 6
\end{aligned}
$$

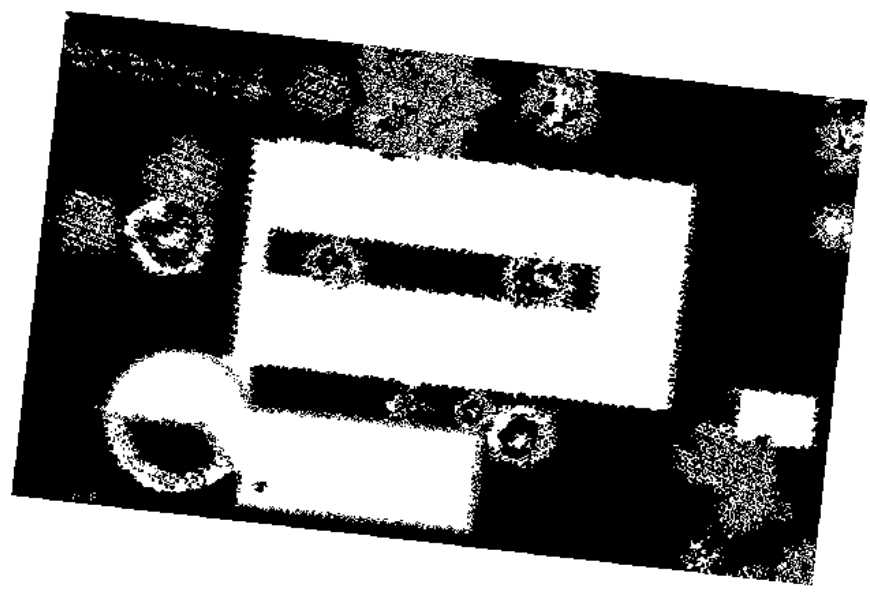

Figura 5 - Imagem binária resultante da reclassificação do fatiamento $\left(f_{4}\right)$. 


\subsection{Filtro de abertura (Morfologia Matemática)}

Esta etapa é utilizada para filtrar apenas as edificações e retirar pequenas áreas que não são de interesse.

Utilizando-se as ferramentas da Morfologia Matemática aplicou-se a Figura 5 (Equação 6), uma erosão $\varepsilon_{B}$ seguida uma dilatação $\delta_{B}$. Este tipo de transformação é também denotado de abertura $\gamma_{B}$, (Equação 6).

$$
\begin{gathered}
f_{5}=\delta_{B}\left(\varepsilon_{B}\left(f_{4}\right)\right) \\
f_{5}=\gamma_{B}\left(f_{4}\right)
\end{gathered}
$$

Com o filtro de abertura $\gamma_{B}\left(f_{4}\right)$, é possível remover parte da vegetação obtendo-se o resultado apresentado na Figura 6. O elemento estruturante $B$ (máscara) define o tamanho do objeto que se deseja eliminar. Se $B$ é pequeno, poucos elementos serão retirados. Quando $B$ aumenta, tem-se também maiores objetos sendo eliminados.

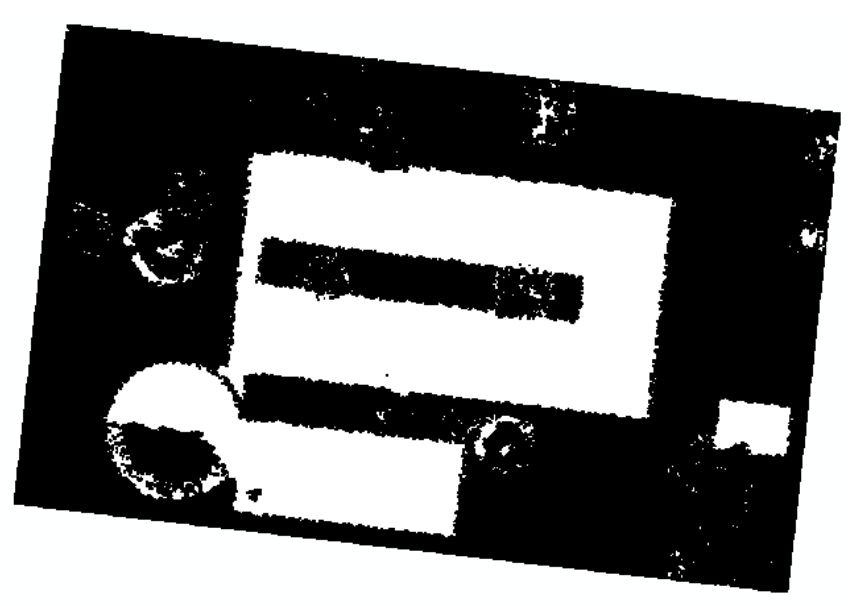

Figura 6 - Imagem binária usando Filtro de abertura (Morfologia Matemática) $\left(f_{5}\right)$.

\subsection{Rotulação de componentes conexas}

A rotulação é um procedimento no qual cada componente conexo irá receber um rótulo (numeração). Os objetos desejados podem ser extraídos de forma manual ou automática.

$\mathrm{Na}$ Figura 6, as edificações ficaram mais visíveis e a maior parte da vegetação foi removida, ficou apenas a vegetação mais densa.
Rotulando-se os objetos conexos da Figura 6, é possível extrair apenas os objetos de interesse conforme a Figura 7 (Equação 7). Este procedimento foi feito aqui de forma manual.

$$
f_{6}=\text { Objetos Conexos de Interesse }\left(\text { Rótulo }\left(f_{5}\right)\right)
$$

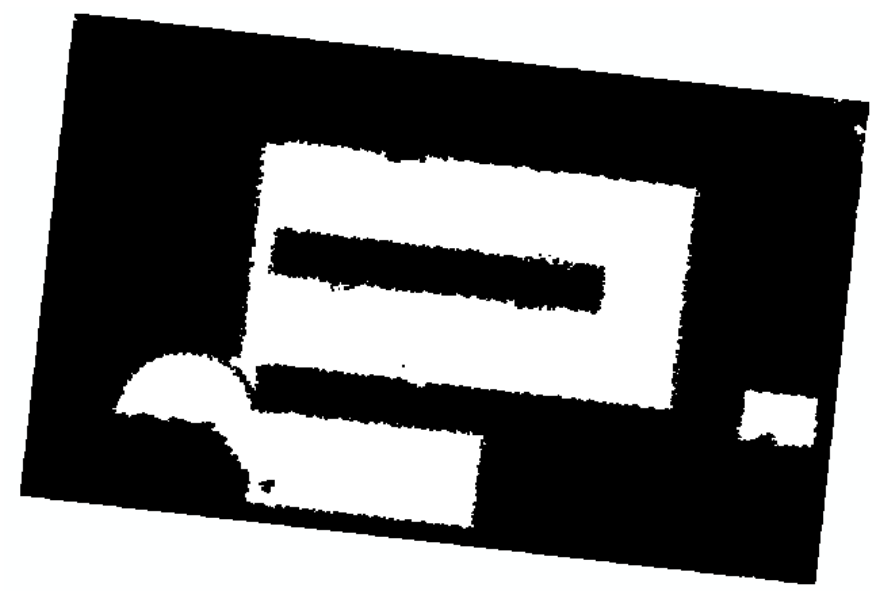

Figura 7 - Imagem binária com os telhados de interesse $\left(f_{6}\right)$. 


\subsection{Extração dos pontos utilizando a máscara}

A partir da intersecção (denotado inf - ínfimo na Morfologia Matemática) entre os planos de informação da máscara $f_{6}$ (Figura 7), e da nuvem de pontos $f_{1}$ (Figura 2), é possível se obter os pontos das áreas edificadas (Equação 8).

$$
f_{7}=\inf \left(f_{6}, f_{1}\right) \text {. }
$$

Estes pontos representam a malha tridimensional dos telhados das edificações da área de estudo, e com estas informações, é possível se obter respostas para diversos questionamentos envolvendo o planejamento e desenvolvimento social do município sob o ponto de vista tridimensional.

Outras interseções podem também ser feitas para gerar novos resultados tais como a máscara $f_{6}$ (Figura 7) com o modelo digital de elevação com altimetria representada em escala de cinza $f_{2}$ (Figura 3 ), e dada pela Equação 9, ou com fatiamento do MDE utilizando oito classes com Natural Breaks $f_{3}$ (Figura 4) e dada pela Equação 10

$$
\begin{aligned}
& f_{8}=\inf \left(f_{6}, f_{2}\right) . \\
& f_{9}=\inf \left(f_{6}, f_{3}\right) .
\end{aligned}
$$

\section{ALGORITMO DESENVOLVIDO}

Nesta seção tem-se em linguagem algorítmica o pseudocódigo desenvolvido para a metodologia que é mostrada a seguir.

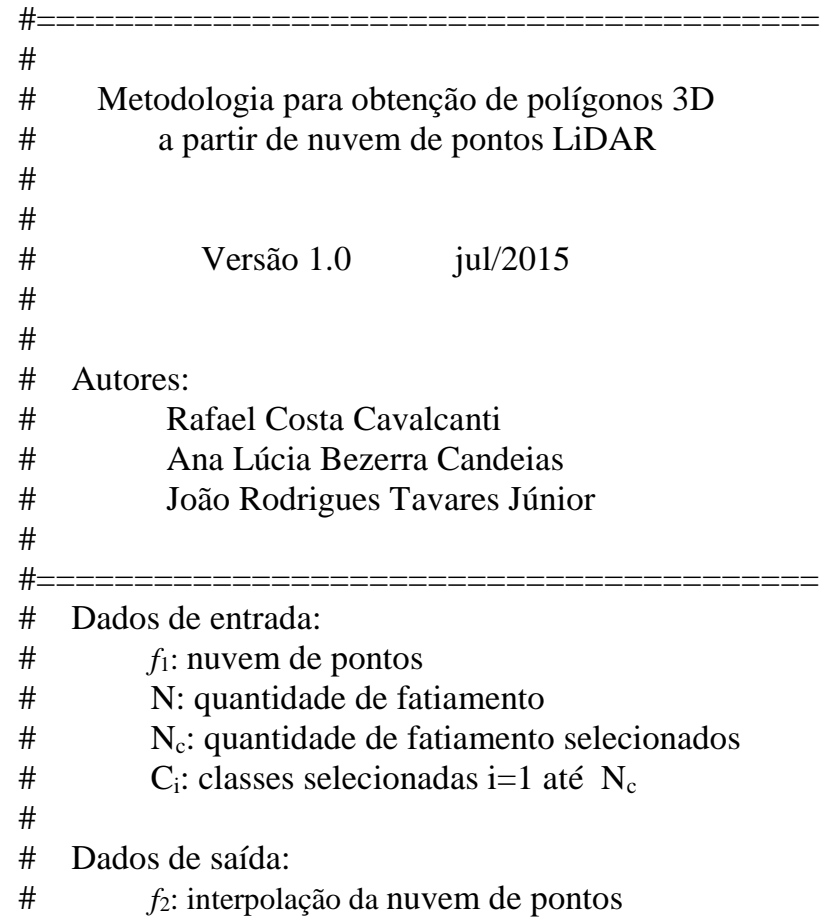

\# $\quad f_{3}$ : resultado do fatiamento de $f_{2}$

\# $\quad f_{4}$ : imagem binária com as classes selecionadas

\# $\quad f_{5}$ : filtragem de pequenos objetos conexos de $f_{4}$

\# $\quad f_{6}$ : rotulação dos objetos conexos em $f_{5}$

\# $\quad f_{7}$ : edificações da nuvem de pontos

\# $\quad f_{8}$ : edificações em escala de cinza

\# $\quad f_{9}$ : edificações do fatiamento

\# Leitura dos dados

1. Entre com a nuvem de pontos $f_{1}$

2. Entre com a quantidade de fatiamento $\mathrm{N}$

\# Metodologia aplicada

3. Calcule:

$f_{2}=$ Interpolação $\left(f_{1}\right)$

4. Calcule:

$f_{3}=$ Slice (" $f_{2} ", 8$, "NATURAL_BREAKS")

5. Escolha quantas $\left(\mathrm{N}_{\mathrm{c}}\right)$ e qual(is) a(s) classe(s) $\mathrm{C}_{\mathrm{i}}$ que será(ão) usada(s) para obter os polígonos 3D

6. Analise as classes de $f_{3}$ e faça a reclassificação:

faça de $\mathrm{i}=0$ até $\mathrm{N}$ se classe $\mathrm{C}_{\mathrm{i}}$ de $f_{3}$ então $\mathrm{C}_{\mathrm{i}}$ em $f_{4}$ igual a 1 caso contrário, $\mathrm{C}_{\mathrm{i}}$ em $f_{4}$ igual a 0

7. Filtragem de objetos conexos usando: abertura $\left(f_{5}=\gamma_{\mathrm{B}}\left(f_{4}\right)\right)$ e eliminando pequenos objetos de tamanho menor que o elemento estruturante $B$.

8. Rotule as componentes conexas:

$f_{6}=$ Objetos Conexos de Interesse $\left(\right.$ Rotulo $\left.\left(f_{5}\right)\right)$

\# Resultado

9. Selecione qual(is) a(s) extrações desejada(s):

a. Edificações da nuvem de pontos: $f_{7}=\inf \left(f_{6}, f_{1}\right)$

b. Edificações em escala de cinza $f_{8}=\operatorname{in} f\left(f_{6}, f_{2}\right)$

c. Edificações do fatiamento 10. fim $f_{9}=$ in $f\left(f_{6}, f_{3}\right)$.

\section{DISCUSSÕES E CONCLUSÃO}

Este trabalho apresentou uma proposta metodológica para aquisição de polígonos 3D georreferenciados a partir da classificação e do tratamento de nuvens de pontos LiDAR. Foi selecionado um recorte da área da Universidade Federal de Pernambuco que continha elementos comuns às diversas áreas do município do Recife. Com isto obteve-se uma simulação de um cenário padrão e, ao mesmo tempo, didático para a apresentação desta proposta metodológica.

Com base nos resultados deste método é possível filtrar informações referentes às áreas e volumes das edificações de municípios e de grandes áreas urbanas. A representação cartográfica destes dados pode ser utilizada de forma quantitativa e qualitativa, porém se aconselha 
uma continuação deste estudo usando diferentes formas de fatiamento e aplicando uma conversão do produto final em polígonos.

Com esta abordagem tem-se uma visualização tridimensional e que pode auxiliar no planejamento e desenvolvimento social do município.

Sugere-se a utilização do python para sintetizar as etapas desta metodologia desenvolvidas e apresentadas como pseudo-código (seção 3) neste artigo.

Também se sugere um estudo a posteriori de teste de hipóteses para análise de resultados obtidos.

\section{AGRADECIMENTOS}

Ao Instituto de Tecnologia de Pernambuco (ITEP/OS), a Prefeitura da Cidade do Recife (PCR) por ceder os dados para este trabalho, ao projeto FACEPE APQ-1405-1.07/12 e ao CNPq processo: 311120/2014-8.

\section{REFERÊNCIAS BIBLIOGRÁFICAS}

BECKER, J. H.; CENTENO, J. A. S.; Avaliação de Métodos de Filtragem de Nuvem de Pontos Derivados do Sistema Laser Scanner Aerotransportado para Obtenção de MDT. Revista Brasileira de Cartografia (2013) $\mathrm{N}^{\circ}$ 65/4: 651-659.

BOTELHO, MOSAR FARIA. Modelagem tridimensional de edificações usando dados do sistema laser scanner $e$ imagem orbital de alta resolução espacial. Tese de Doutorado. Universidade Federal do Paraná. Programa de Pós-Graduação em Ciências Geodésicas. Curitiba, 2007.

CANDEIAS, A. L. B. Aplicação da Morfologia Matemática e Analise de Imagens de Sensoriamento Remoto. Tese de Doutorado. INPE, 6340 - TDI/592. Instituto Nacional de Pesquisas Espaciais. 1997

CANDEIAS, A. L. B., MOURA, C. J. M, NASCIMENTO, P. H. O., TAVARES JR, J. R. Extração de Borda de Reservatório: Uma análise pela Morfologia Matemática. VIII Colóquio Brasileiro de Ciências Geodésicas, 2013.

CAVALCANTI, R. C., TAVARES JR, J. R., CANDEIAS, A. L. B. Simulação de Mapeamento de Riscos de Inundações usando Dados Lidar: Estudo de Caso da Bacia do Rio Una - PE. Revista Brasileira de Cartografia (2013) No 65/4: 703-716.

CHEN, Q.; GONG, P.; BALDOCCHI, D.; XIN, G. Filtering Airborne LASER Scanning Data with Morphological Methods. Photogrammetric Engineering \& Remote Sensing, v. 73 (2), pp. 175-185, 2007.

ITEP - Instituto de Tecnologia de Pernambuco. Relatório de Validação de Dados dos Aerolevantamento da Perfeitura da Cidade do Recife - Cidade do Recife, 2013.
HARALICK, R. M.; STERNBERG, S.R.; ZHUANG, X., Image analysis using mathematical morphology, IEEE Pattern Anal. Machine Intell., vol. PAMI-9, no. 4, pp. 532-555, Jul., 1987.

PACHECO, A. P.; CENTENO, J. A. S.; DE ASSUNÇÃO, M. G. T.; MOSAR FARIA BOTELHO, M. F. Classificação de pontos LIDAR para a geração do MDT. Bol. Ciênc. Geod., sec. Artigos, Curitiba, v. 17, No 3, p.417-438, jul-set, 2011. 